\title{
UM MÉTODO PARA APOIO À LEITURA BASEADO NO USO DE UMA FERRAMENTA DE MINERAÇÃO DE TEXTO
}

\author{
Juliana de Campos Hessler - UFRGS - julianahessler@yahoo.com.br \\ Eliseo Reategui - PPGEDU/PPGIE - UFRGS - eliseoreategui@gmail.com
}

\begin{abstract}
Resumo: Este artigo apresenta uma investigação sobre a leitura e estratégias que podem ser utilizadas para auxiliar o aluno no entendimento de textos, explicitando como o uso de uma ferramenta de mineração de texto pode facilitar este processo. Um apanhado teórico sobre leitura e letramento é apresentado no artigo. Em seguida, propõe-se um método para uso de uma ferramenta de mineração de texto como forma de apoio à leitura. $O$ artigo apresenta então um experimento sobre a utilização de tal método com vinte estudantes da 5 a série para leitura de um texto literário. Os resultados do experimento demonstraram que o método permitiu aos alunos explorar o texto e compreendê-lo de forma mais aprofundada.
\end{abstract}

Palavras-chave: leitura, compreensão textual, mineração de textos

\section{A METHOD TO SUPPORT READING BASED ON THE USE OF A TEXT MINING TOOL}

\begin{abstract}
This article presents and investigation about reading and strategies which may be used to help the student in the understanding of texts, describing how the use of a text mining tool can support this process. A theoretical background about reading and literacy is presented in the paper. Then, a method for the use of a particular text mining tool is proposed as a way to support reading. After that, the paper presents an experiment about the use of such method with twenty $5^{\text {th }}$ grade students who had to read a literature text. The results of the experiment demonstrated that the method enabled the students to explore the text and have a deeper understanding of it.
\end{abstract}

Keywords: leitura, compreensão textual, mineração de textos

\section{Introdução}

Nos dias atuais é cada vez mais perceptível a importância da leitura. O uso da linguagem como forma de comunicação inicia bastante cedo, em nossas casas. Este uso vai se multiplicando na medida em que somos alfabetizados, avançamos na escola e chegamos à universidade, onde somos imersos por vários anos em um mundo onde precisamos necessariamente compreender a linguagem escrita, uma das principais formas de comunicação empregadas (STICHT et al, 1974). Para Magda Soares (1998) dentre as muitas habilidades/capacidades, a leitura inclui as de fazer previsões sobre o texto, de construir 
significado combinando conhecimento prévio e informação textual, de refletir sobre o significado do que foi lido e tirar conclusões sobre o assunto enfocado.

Nosso aluno tem contato diário com diversos tipos de leitura, desde o impresso ao digital. Dizer, então, que o aluno não gosta de ler não pode ser inteiramente verdade. Talvez ele seja mais resistente a uma leitura mais extensa quando é necessário dispor de mais tempo e concentração. No momento em que utiliza uma ferramenta da Internet, como o Messenger, por exemplo, a leitura é mais dinâmica, assim como sua assimilação. Muitos ainda conseguem ser hábeis a ponto de conversarem virtualmente com dezenas de pessoas simultaneamente.

Diversos são os estudos a respeito de leitura e seus hábitos. Um dos mais completos a nível nacional é a pesquisa realizada pelo Instituto Pró-Livro, intitulada de "Retratos da leitura no Brasil"(2008). As dificuldades de leitura que foram declaradas pelos entrevistados mostram que as habilidades leitoras podem decorrer da fragilidade do processo educacional, ou seja, o problema começa na escola, onde deveria ser um local de tentativa de solução dos mesmos. Embora essa declaração seja importante, a pesquisa ainda observou que, grande parte dos entrevistados, não teve influência de leitura também dentro de seus lares. Muitos entrevistados ainda alegraram que não leem porque não estão estudando. Dado esse que nos faz refletir que as pessoas acreditam que a leitura precisa ocorrer necessariamente somente dentro do ambiente escolar e que as tentativas de formar esses cidadãos leitores não foram bem sucedidas. No momento em que um aluno torna-se leitor, ele passa a criar o hábito de ler sem ser obrigado a fazê-lo.

A pesquisa em questão utilizou como conceito de leitor aquele que leu, pelo menos, um livro nos últimos três meses, enquanto que o não-leitor aquele que não leu nenhum livro nesse mesmo período. Ressalta que, sendo uma pesquisa de opinião, não analisou os dados sobre qualidade e compreensão de leitura. A pesquisa apontou que, das cinco regiões brasileiras, a região Sul é aquela que lê com mais frequência. Além disso, a população dessa região lê aproximadamente 5,5 livros por ano. A maior taxa de leitores concentrou-se na população de 5 a 10 anos, e essa idade (10 anos) também é a fase em que os leitores mais leram na vida. Esse último dado é preocupante, pois a criança de 10 anos encontra-se ainda nas séries iniciais. Sendo assim, quando ela inicia as séries finais do ensino fundamental ela diminui seu ritmo de leitura.

Este artigo apresenta um estudo sobre como o uso da tecnologia, mais precisamente uma ferramenta de mineração de texto, pode auxiliar o aluno a desenvolver mais e melhor sua habilidade de compreensão leitora.

\section{O Letramento}

Quando abordamos o termo "leitura", não podemos deixá-lo dissociado da expressão "letramento", pois esse é adquirido com bons hábitos de leitura. O letramento compreende tanto a apropriação das técnicas para a alfabetização quanto o aspecto de convívio e o hábito de utilização da leitura e da escrita (SOARES, 2003). Ser letrado é ler, escrever e utilizar eficientemente a Língua como forma de comunicação e expressão e não apenas saber assinar o próprio nome ou elaborar pequenos textos. Qualquer pessoa pode ser letrada, o que não quer dizer que ela saiba ler e escrever. Esse caso é notável em crianças que ainda não são alfabetizadas e mantém contato com livros desde cedo. Elas aprendem desde pequenas as diversas formas de comunicação e passam a tornar-se conhecedoras dos vários gêneros textuais existentes. Em contrapartida, não necessariamente aquele que sabe ler é considerado letrado. 
O que se percebe em nosso país é um grande número de pessoas que são alfabetizadas, mas não sabem como utilizar seus conhecimentos, o que chamamos de "analfabetismo funcional". O Brasil apresenta um crescimento considerável de crianças na escola desde seus primeiros anos de vida, o que acarreta em uma diminuição do número de analfabetos. Conforme pesquisa realizada pelo Instituto Paulo Montenegro, chamada de INAF Brasil (2007), em 1995, 77,9\% das crianças e jovens entre 4 e 17 anos frequentavam a escola. No ano de 2008, esse índice aumentou para 91,5\%. Essa estatística se amplia ainda mais na faixa de idade entre 7 e 14 anos: 85,9\% em 1995 e 97,9\% em 2008. O acesso à escolarização tornou-se mais amplo e atualmente há várias iniciativas que valorizam e estimulam a frequência das crianças no ambiente escolar, porém, é importante lembrar que o acesso e a permanência das crianças e adolescentes na escola não garantem certas habilidades de leitura necessárias para o desempenho crítico e autônomo dos alunos.

$\mathrm{O}$ que se tem percebido dentro e fora das escolas é que muitos indivíduos são e foram alfabetizados sem a preocupação de uma compreensão leitora e o que ocorre como consequência é a falta dessa habilidade que, dentro da escola, não é percebida somente na disciplina de Língua Portuguesa, visto que todas as outras áreas fazem uso da mesma. Uma revista de grande circulação no país divulgou certa vez que "o melhor termômetro para aferir o grau de aprendizado do estudante é, segundo os especialistas, sua capacidade de ler e interpretar um texto: quanto mais precária ela for, mais difícil será para ele absorver conhecimento em outras matérias. (WEINBERG e EDWARD, 2005, p. 72).

\section{Processos de Leitura}

Quando percebemos que um aluno não tem o hábito da leitura e está somente alfabetizado, deparamo-nos com mais uma problemática: a falta de significado que o texto vai apresentar para esse indivíduo. O processo de leitura não apresenta o leitor como passivo, ou seja, o que ele extrai de um texto não é inconsciente. A construção do texto vai delimitando sua compreensão e é por esse motivo é importante que o aluno conquiste o hábito de ler, que esteja atento à função que cada palavra exerce no contexto.

Marchuski (2009) assegura que a maioria dos livros didáticos perde uma oportunidade de treinar o raciocínio, o pensamento crítico, habilidades argumentativas e a formação de opinião, visto que esses livros tratam o texto como se fossem monossemânticos, ou seja, com um único sentido sem dar chance ao leitor de criar suas próprias hipóteses e teorias. Faz uma crítica exacerbada quanto ao modo de apresentação e à tipologia de perguntas encontradas nos manuais de Língua Portuguesa existentes nas escolas brasileiras. O autor propõe algumas sugestões de como trabalhar com compreensão de texto desde a identificação das ideias centrais do texto, realização de perguntas inferenciais, reprodução de conteúdo em outro gênero textual até trabalhos de revisão e compreensão.

Em um processo de compreensão de leitura podemos encontrar como fator importante o conhecimento prévio. Essa compreensão está condicionada pelo contexto social e cultural do sujeito. Para entender certas informações presentes nos textos, temos que acionar nosso conhecimento de mundo (crenças, experiências, ideologias, histórias e contextos da cultura em que estamos inseridos). Conforme Kleiman (2002), "o conjunto de noções e conceito sobre o texto faz parte do conhecimento prévio e desempenha um papel importante na compreensão de texto". Sendo assim, o papel do leitor é fundamental para a compreensão de leitura e cada um poderá ter uma visão diferente da realidade, pois só ele poderá trazer significado particular ao texto. 
Shanahan (2008) aponta ainda para processos e estruturas cognitivas envolvidos nas atividades de leitura e de escrita, tais como habilidades visuais, fonológicas, sistema semântico, memória de curta e longa duração. Neste sentido, o autor afirma que qualquer instrumento que possibilite o desenvolvimento de algum destes processos ou estruturas pode representar um importante avanço. Tendo em vista que um texto necessita ter sua compreensão construída a partir das etapas de um processo de leitura, propomos aqui uma ferramenta que atua em algumas destas etapas buscando colaborar no desenvolvimento de habilidades ao nível do sistema semântico. A próxima seção aborda o uso da tecnologia como apoio aos processos de leitura e escrita, e apresenta a ferramenta de mineração de textos SOBEK, mostrando como esta pode ser empregada em atividades de leitura e compreensão textual.

\section{A Tecnologia como apoio à Leitura/Escrita/Compreensão}

A ferramenta SOBEK foi idealizada como recurso de apoio aos professores no acompanhamento de trabalhos de escrita colaborativa (Macedo et al., 2009). Foi também adaptada para ser utilizada com os próprios alunos - como forma de auxiliá-los no processo de produção textual (KLEMANN et al., 2009).

A ferramenta opera da seguinte maneira:

(1) Copia-se o texto que se quer trabalhar para a área de entrada de dados da ferramenta. Alternativamente, carrega-se um texto em formato $t x t$, doc ou $p d f$. A figura 1 mostra a ferramenta com um texto sobre o tema "a Escrita".

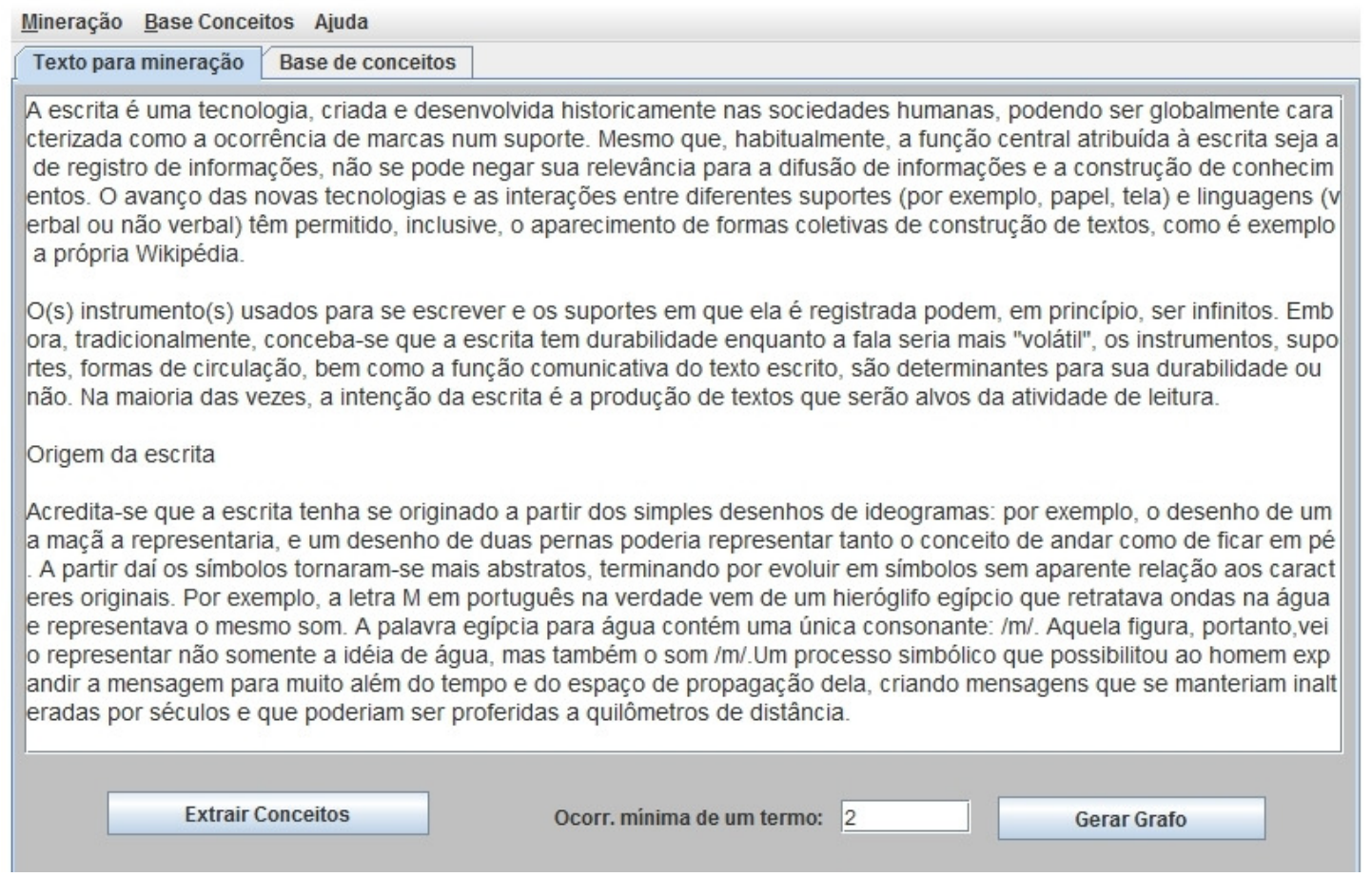

Figura 1 - Ferramenta SOBEK

(2) A partir deste texto, cria-se uma base de conceitos automaticamente através do processo de mineração de textos (botão "Extrair Conceitos", figura 1). Estes

\footnotetext{
${ }^{1}$ Texto introdutório do artigo "Escrita", extraído da enciclopédia Wikipedia, disponível no endereço: http://pt.wikipedia.org/wiki/Escrita, acessado em agosto de 2009 .
}

V. $8 \mathrm{~N}^{\mathrm{o}} 3$, dezembro, 2010 
conceitos correspondem a um conjunto de palavras e termos que ocorrem com mais frequiência no texto, excluindo-se artigos, preposições, e outras palavras consideradas sem significado relevante ${ }^{2}$. O parâmetro "ocorrência mínima de um termo" (figura 1) permite que apenas termos com freqüência maior que o limite estabelecido sejam considerados na extração de conceitos.

(3) Extraídos os conceitos, gera-se um grafo com os conceitos mais freqüentes e seus relacionamentos. O exemplo da figura 2 mostra o grafo gerado para o texto sobre o tema "a Escrita".

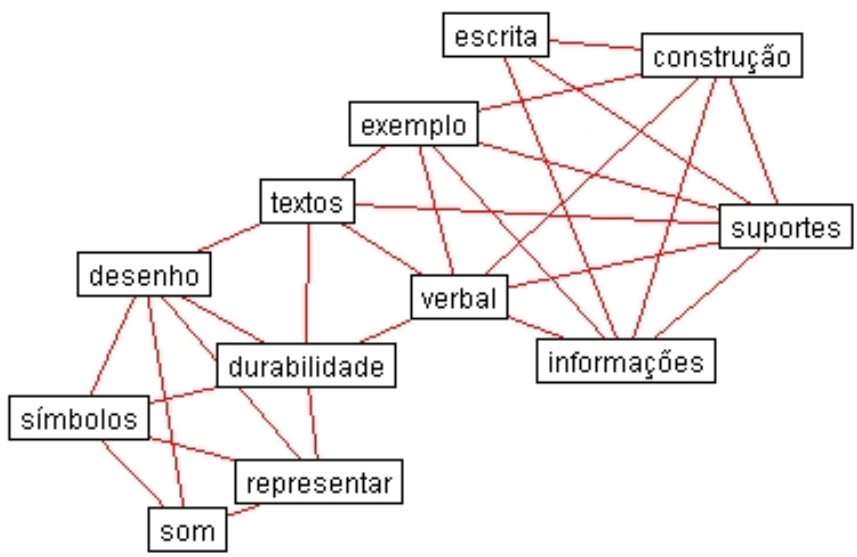

Figura 2 - Grafo gerado para o texto sobre o tema "a Escrita"

A partir do exemplo exposto, percebe-se que os termos extraídos do texto são efetivamente relevantes com relação ao tema tratado. O processo utilizado pela ferramenta na realização desta tarefa é conhecido como mineração de texto. Este processo é definido como um método de extração de informações relevantes em bases de dados não estruturadas, ou semiestruturadas (Feldman e Sanger, 2006). No caso da ferramenta SOBEK, um algoritmo específico definido por Shanker (2003) foi implementado, baseado em análises estatísticas dos textos e representação das informações extraídas em um modelo de grafo chamado de distância n-simples (n-simple distance).

$\mathrm{Na}$ investigação aqui apresentada, buscamos mostrar como a ferramenta SOBEK pode ser empregada como apoio à compreensão textual, auxiliando os estudantes na identificação de conceitos relevantes em um texto. Como citado anteriormente, a implementação de ferramentas que possibilitem o desenvolvimento de processos ou estruturas cognitivas envolvidos nas atividades de leitura podem representar uma contribuição importante no processos de letramento (Shanahan, 2008). Assim, nossa proposta é empregar a ferramenta SOBEK como facilitadora no desenvolvimento de habilidades ao nível do sistema semântico dos leitores, através de um mecanismo que instiga os alunos a se questionarem sobre os principais conceitos e termos presentes em um texto, bem como sobre a forma com que estes se relacionam.

Hughes (2007) afirma que o principal componente do sistema semântico é o vocabulário. Um leitor precisa ser capaz de associar significado a palavras e ter algum conhecimento prévio para utilizar como contexto para compreender a palavra. Devem ser capazes de relacionar uma nova palavra ao conhecimento prévio através de associações próprias com o texto e sua

\footnotetext{
${ }^{2} \mathrm{O}$ sistema permite utilizar uma lista chamada de stop-words com termos a serem desconsiderados do processo de mineração. Atualmente a ferramenta trabalha com listas de stop-words em português e em inglês, mas facilmente pode ser adaptada para outras línguas.
}

V. $8 \mathrm{~N}^{\mathrm{o}} 3$, dezembro, 2010 
estrutura. A autora aponta ainda que uma forma de dar suporte ao desenvolvimento do sistema semântico pode envolver:
a) Perguntar se "isto faz sentido?"
b) Ativar o conhecimento antigo para apoiar novas aprendizagens
c) Falar aos estudantes sobre os objetivos e funções do letramento
d) Apoiar os estudantes em tarefas que eles conseguem fazer e desafiá-los a ir um pouco além
e) Utilizar um quadro de palavras

Com base nestas diretrizes, concebeu-se o seguinte método como estratégia de leitura e compreensão de texto envolvendo a ferramenta de mineração SOBEK:

1) Leitura individual de um texto;

2) Utilização da ferramenta SOBEK para identificação de termos relevantes e geração de grafo. Ao gerar uma representação gráfica dos principais termos de um texto, esta tarefa pode ser vista como uma forma análoga de criação de um quadro de palavras (item $e$ da enumeração anterior);

3) Discussão sobre os termos identificados pela ferramenta como mais relevantes, instigando os alunos a se perguntarem se "isto faz sentido" (item $a$ da enumeração anterior)

4) Discussão sobre as relações identificadas pela ferramenta entre os termos apontados como mais relevantes. Aqui, além de instigar os alunos sobre a importância das relações entre termos (item $a$ ), a tarefa leva-os a ativar seu conhecimento prévio na busca de possíveis interpretações para estes relacionamentos (item $b$ );

5) Re-estruturação do grafo fazendo as mudanças consideradas apropriadas com base nas discussões realizadas. Esta tarefa se relaciona novamente à criação do quadro de palavras mencionado no item $e$.

A importância de se ressaltar os objetivos e funções do letramento (item $c$ ) não consta explicitamente no método delineado, já que este esclarecimento não contribui diretamente na compreensão de determinada leitura. Entende-se, no entanto, que enfatizar a importância e objetivos do letramento seja incumbência constante do professor. Quanto ao item $d$ da enumeração anterior, entende-se que a proposta de desafios não esteja necessariamente ligada à realização de uma dada tarefa, mas sim, que esteja relacionada à forma como o professor percebe cada aluno e explora a atividade. Neste sentido, a maior parte das tarefas propostas no método permitem ao professor explorá-las como desafios que exigem do aluno ir um passo além.

A próxima seção descreve um experimento realizado utilizando a ferramenta SOBEK em uma atividade com alunos de uma escola pública no sul do país.

\section{Experimentação e Resultados}

O experimento aqui apresentado foi realizado em uma escola da Rede Municipal de Portão, RS. Essa escola está inserida em um bairro com uma grande quantidade de alunos muito carentes. Talvez por esse motivo, é perceptível a ausência do estímulo à leitura nos lares dos alunos. Porém, dentro do ambiente escolar, o aluno tem muito contato com materiais impressos. Sabe-se mesmo assim que a leitura é adquirida através do hábito constante do ato 
de ler e que escola e família precisam tratar juntos desse problema. A falta desse hábito acaba acarretando deficiências na habilidade de compreensão textual de alguns discentes da escola.

Desenvolveu-se então uma atividade de leitura com uma turma de $5^{\text {a }}$ série que conta com vinte alunos na faixa etária entre 10 e 12 anos. Eles são muito concentrados, questionadores e participativos e gostam muito de atividades diferenciadas. Alguns deles apresentam problemas de compreensão de leitura mais destacados e ainda há alguns resistentes que não apreciam esse tipo de atividade. Com o propósito de investigar a utilização da ferramenta SOBEK no auxílio da compreensão de leitura, as seguintes atividades foram propostas, buscando fazer com que o aluno refletisse mais sobre o que lê.

1) Leitura individual do texto "A velha contrabandista", de Stanislaw Ponte Preta;

2) Resposta individual a uma breve lista de questões sobre o texto. Esta lista de questões teve como objetivo verificar o quanto os alunos realmente compreenderam do texto antes da atividade com a ferramenta SOBEK.

3) Apresentação da ferramenta SOBEK. Atividade desenvolvida em grupo, utilizando um projetor multimídia;

4) Extração de conceitos e criação de grafo a partir do texto lido; Atividade também desenvolvida em grupo.

5) Discussão sobre os termos e relações identificados pela ferramenta como mais relevantes

6) Re-estruturação do grafo a partir da discussão realizada

7) Elaboração de um resumo a partir do novo grafo;

8) Discussão das respostas de compreensão;

9) Análise oral da atividade realizada e verificação sobre a percepção dos alunos quanto ao uso da ferramenta como apoio à leitura

A realização da leitura através de um texto impresso, além de permitir aos alunos trabalharem neste momento individualmente, lhes permitiu também realizar a releitura, o que pode oferecer subsídios como apontar novas direções de maneira a esclarecer dúvidas, evidenciar aspectos antes despercebidos ou subestimados, apurar a consciência crítica acerca do texto, proporcionar novos elementos de comparação (PERUCHI et al., 2007). Quanto ao conhecimento de mundo, ou conhecimento prévio, este é o conhecimento que o leitor tem sobre o assunto que lhe permite fazer inferências necessárias para relacionar diferentes partes do texto num todo coerente". Acreditamos que, na atividade individual, muitos alunos tenham tido sua compreensão textual comprometida por não terem conseguido ativar seu conhecimento de mundo: palavras como "alfândega", "muamba" e "contrabando" não foram compreendidas em seu sentido pleno e, no texto, eram fundamentais para chegar-se à conclusão dos acontecimentos da história.

Após a leitura silenciosa do texto, os alunos receberam também de forma impressa algumas questões de compreensão para responderem individualmente, com o objetivo de avaliarmos seu nível de compreensão do texto em um primeiro momento. Assim que todos terminaram, pedimos que permanecessem com suas folhas de respostas, porém ficou combinado que, a partir dali, não responderiam mais a nenhuma questão.

Apresentamos a eles, então, a ferramenta SOBEK e explicamos a sua utilização. Como já estavam habituados a fazer mapas conceituais em outras disciplinas, não apresentaram dificuldade em compreender sua funcionalidade. Mostramos que, em um primeiro momento, 
era necessário importar ou colar o texto, no nosso caso "A velha contrabandista", na tela em branco da ferramenta. Em seguida extraímos os conceitos e, posteriormente, geramos o grafo, conforme o exemplo da figura 3.

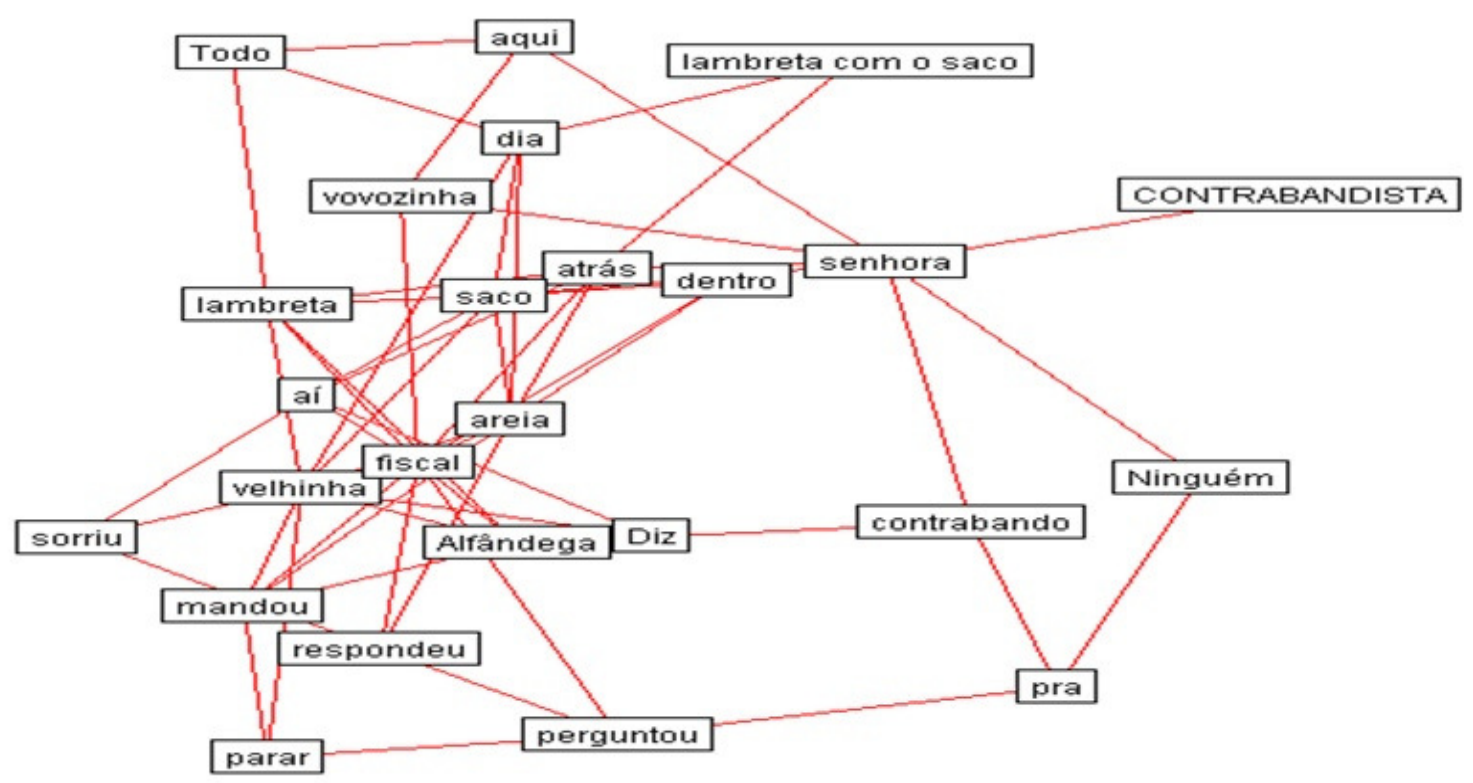

Figura 3: Grafo gerado a partir do texto "A velha contrabandista"

A partir daí, começamos a observar as palavras contidas no grafo e a verificar se todas elas realmente eram importantes para a compreensão do texto. Os alunos acreditaram que nem todas precisariam fazer parte do mesmo e começamos a discutir e a excluir as palavras menos relevantes. Cada aluno esboçou um grafo com estas alterações, e então foi solicitado a todos que elaborassem um texto utilizando somente os termos considerados mais relevantes. $\mathrm{O}$ objetivo também era que cada um escrevesse um pequeno resumo do texto e percebesse se as palavras excluídas realmente não eram importantes para a compreensão. Logo no início da atividade, pudemos perceber que alguns alunos já haviam sentido falta de algumas palavras, pois no momento da escrita tiveram seus textos prejudicados no entendimento.

Ao término da tarefa, voltamos a discutir se as palavras excluídas realmente não eram tão importantes quanto pareciam em um primeiro momento. Foi interessante perceber quem realmente conseguiu fazer uso da ferramenta para conduzir seu processo de compreensão textual e também observar que as palavras que eram desnecessárias em uma primeira leitura, passaram a tornar-se importantes depois de uma análise mais aprofundada. Alguns quiseram realizar a leitura oral de seus resumos e os próprios colegas analisavam se eles realmente conseguiram abstrair a ideia central do texto ou não.

Por fim, conforme afirma Magda Soares (1998) é importante que haja uma reflexão do significado do que foi lido para que possam ser tiradas conclusões sobre o assunto em questão. Por esse motivo, demos uma atenção à análise das respostas de forma oral para contemplar a participação na exposição de ideias e o questionamento quanto às respostas. Pudemos perceber que, aqueles que não haviam respondido por escrito todas as respostas do questionário após a primeira leitura do texto, conseguiram fazê-lo depois da atividade com a ferramenta SOBEK. Foi possível perceber também, com a realização da atividade, um aprofundamento considerável na forma como a maior parte dos alunos complementou suas respostas. Apesar do êxito destes, foi também percebido que alguns estudantes não haviam entendido o texto como um todo mesmo após a atividade. Trata-se de estudantes com mais 
dificuldade que necessitariam realizar este tipo de prática com mais frequência. $O$ fato da ferramenta SOBEK ser de fácil utilização pode possibilitar a estes estudantes realizar suas leituras individualmente empregando o método proposto, dando-lhes a possibilidade de explorar os textos de maneira sistemática e assim possibilitar que melhorem suas habilidades de compreensão leitora.

\section{Considerações Finais}

A principal contribuição desse trabalho foi avaliar de que maneira a utilização de uma ferramenta de mineração de texto poderia contribuir como instrumento pedagógico na compreensão textual. Um experimento realizado com vinte estudantes de uma escola pública demonstrou que a maior parte dos alunos aprofundou bastante seu entendimento de um texto lido após a realização de uma atividade utilizando a ferramenta de mineração SOBEK. Praticamente todos os estudantes consideraram a ferramenta como facilitadora do entendimento e compreensão leitora. Acreditamos que atividades diferenciadas utilizando esse tipo de recurso podem estimular o educando a ser mais participativo e autônomo em suas ideias e ações no cotidiano escolar.

Outro fator importante de ser ressaltado foi a motivação dos alunos na realização da atividade aqui proposta. Visto que a deficiência de compreensão leitora alcança índices altos, é preciso que cada vez mais se procure alternativas para que esses problemas sejam sanados. Sabemos que não serão excluídos de imediato, mas temos o papel de orientar nosso aluno para que consiga organizar suas ideias e compreender mais e melhor o que lê.

Como trabalhos futuros, considera-se a possibilidade de trabalhar com um grupo de estudantes com dificuldades de compreensão textual durante um período mais extenso, empregando o método proposto como principal estratégia de leitura. Desta forma, poderíamos identificar maneiras de ampliar o método e a ferramenta de mineração de texto propostos para que pudessem apoiar de forma mais adequada estes estudantes.

\section{Referências}

COSTA, Patrícia S. Campelo; REATEGUI, Eliseo. O Papel das Ferramentas Digitais no Letramento através de Narrativas Fanfiction. RENOTE. Revista Novas Tecnologias na Educação, 2010.

FELDMAN, R., SANGER, J. Text Mining Handbook. Cambridge, Inglaterra: Cambridge University Press, 2006.

HUGHES, J. M. Teaching Language and Literacy: The Four Cueing Systems. University of Ontario Institute of Technology, 2007. Disponível em: http://faculty.uoit.ca/hughes/Oral_Visual_Literacy/CueingSystems.html. Acessado em Outubro de 2010.

INAF. Indicador de Alfabetismo Funcional. Instituto Paulo Montenegro. 2007. Disponível em <http://www.ipm.org.br/ipmb_pagina.php?mpg=4.02.02.00.00\&ver=por $>$. Acesso em setembro 2010. 
KLEIMAN, Ângela. Texto e Leitor: Aspectos Cognitivos da Leitura. 8 ed. Campinas: Pontes, 2002.

KLEMANN, M., LORENZATTI, A., REATEGUI, E. O Emprego da Ferramenta de Mineração de Textos SOBEK como Apoio à Produção Textual. Em Anais do Simpósio Brasileiro de Informática na Educação, 2009, Florianópolis.

MACEDO, A., Reategui, E., Lorenzatti, A., Behar, P. Using Text-Mining to Support the Evaluation of Texts Produced Collaboratively. Education and Technology for a Better World: Selected papers of the 9th World Conference on Computers in Education, Bento Gonçalves, Brazil. Springer, 2009.

MARCUSCHI, L. A. Compreensão de texto: algumas reflexões. In. DIONISIO, A. P. \& BEZERRA, M. A. (orgs.) O livro didático de Português: múltiplos olhares. $2^{\mathrm{a}}$ ed. Rio de Janeiro: Lucerna, 2003.

PERUCHI, Ivanilde Minzon; GOMES, Janaína Prado; CEZAR, Marcela. A importância da leitura. 2007.2 Disponível em $<\mathrm{http}: / /$ faculdadesdombosco.edu.br/v2.1/documentos/monografia_marcela.pdf $>$ Acesso em outubro de 2010.

RETRATOS DA LEITURA NO BRASIL. Instituto Pró-livro. 2008. Disponível em <www.prolivro.org.br/ipl/publier4.0/dados/.../48.pdf.> Acesso em setembro 2010.

SHANAHAN, T. Relations among Oral Language, Reading, and Writing Development. Handbook of Writing Research. MacArthur, C., Graham, S. e Fitzgerald, J. (Eds.). New York: The Guilford Press, 2008. P. 171-183.

STICHT, T. G., BECK, L. J., HAUKE, R. N., KLEIMAN, G. M., JAMES, J. H. Auding and Reading: a Developmental Model. Alexandria, Virginia: Human Resources Research Organization. 1974.

SOARES, Magda Becker. Letramento: um tema em três gêneros. Belo Horizonte: Autêntica, 1998.

SOARES, Magda Becker. O que é letramento. Diário do Grande ABC, Santo André, 29 de agosto de 2003. Diário na Escola, p. 3.

PRETA, Stanislaw Ponte. A velha contrabandista. Disponível em $<$ http://www.pensador.info/autor/Stanislaw_Ponte_Preta> Acesso em outubro de 2010.

WEINBERG, M. EDWARD, J. Na trilha coreana. Revista Veja, São Paulo: Editora Abril, ano 38, n.7, p.72, 16 fev. 2005. 